\title{
Photocatalytic Properties of Sisal Fiber Coated with Nano Titanium Dioxide
}

\author{
Fernando R. Oliveira ${ }^{\text {a }}$, Felipe M.F. Galvão a, José Heriberto O. do Nascimento ${ }^{\text {a }}$, Kesia \\ Karina O. S. Silva ${ }^{\mathrm{a}}$, José Ivan Medeiros ${ }^{\mathrm{a}}$, Andrea Zille ${ }^{\mathrm{b}}$ \\ ${ }^{a}$ Departamento de Engenharia Têxtil, Universidade Federal do Rio Grande do Norte UFRN, 59.072-970, Natal, Brazil \\ ${ }^{b} 2$ C2T - Centro de Ciência e Tecnologia Têxtil, Departamento de Engenharia Têxtil, Universidade do Minho, 4800-058 Guimarães, Portugal
}

\begin{abstract}
Molded sisal fibers dip-coated with titanium dioxide $\left(\mathrm{TiO}_{2}\right)$ nanoparticles were physico-chemical characterized and tested for the photocatalytic treatment of textile wastewaters. The X-Ray powder diffraction (XRD), X-Ray photoelectron spectroscopy (XPS), atomic force microscopy (AFM) and the scanning electron microscopy (SEM) analysis revealed uniform $\mathrm{TiO}_{2}$ nanoparticles deposition in the anatase phase with and average diameter of $32 \mathrm{~nm}$. The sisal/ $\mathrm{TiO}_{2}$ nanocomposite exhibits a remarkable photodegradation yield of methylene blue solution (92\%) maintaining a good efficiency even after 5 washing cycles (70\%). The nanocomposite also exhibits a remarkable fast photo-induced hydrophilicity decreasing the contact angle from $140^{\circ}$ to $6^{\circ}$ after 7 minutes of UV exposure. Sisal fibers revealed to be a promising substrate for $\mathrm{TiO}_{2}$ nanocomposites in wastewater treatment due to its low cost, low density, high specific strength and modulus, no health risk, easy availability and renewability.
\end{abstract}

Selection and peer-review under responsibility of TEMA - Centre for Mechanical Technology and Automation.

Keywords: Sisal; titanium dioxide; nanoparticle; composite; wastewater; photocataslysis

\section{Introduction}

The use of metallic semiconductors and polymeric nanocoatings on flexible substrates (e.g. films and fibers) has received greatly attention mainly due its potential application in monitoring and decomposition of various environmental pollutants, such as dyeing effluent, gases, wastewater produced in oil refining, among others. ${ }^{1,2}$ The 
main nanocoatings currently studied are: (i) The base metal ions of silver and copper due to their antimicrobial and conductive properties; (ii) $\mathrm{ZnO}$ and $\mathrm{TiO}_{2}$ semiconductors due to excellent $\mathrm{UV}$ protection, antimicrobial and photocatalytic properties. Among all oxides, $\mathrm{TiO}_{2}$ is one of the most widely used semiconductors to obtaining functional materials due to its unique properties such as low toxicity, high chemical stability, low cost and outstanding photocatalytic activity. ${ }^{3-6}$ The most commonly used $\mathrm{TiO}_{2}$ morphology is that of monodispersed nanoparticles wherein the diameter is controlled to give benefits from the small crystallite size with high surface area and reduced bulk recombination. ${ }^{7}$ Over the last two decades, photocatalysis with $\mathrm{TiO}_{2}$ nanoparticles has been shown useful for the treatment of wastewaters due to the possibility to achieve complete mineralization of organic pollutants at mild pressures and temperatures without solid waste formation. ${ }^{8}$ However, despite the high efficiency of the photodegradation process, the use of $\mathrm{TiO}_{2}$ nanoparticles in suspension is troublesome because of the formation of aggregates, limitation in the UV penetration, difficult separation and recycling. These complications can be overcome by the immobilization of $\mathrm{TiO}_{2}$ in solid supports as bound particles or thin solid films. ${ }^{9,10}$ However, the high cost and the environmental concerns on the use of synthetic fibers and resins derived from petroleum contribute to the development of research activities on natural composites. ${ }^{11}$ Polymeric composites reinforced with natural fibers, including titanium nanoparticles on flexible substrates such as textile fiber, yarns and fabrics, have been developed in recent years, showing significant potential for various engineering applications due to their intrinsic sustainability, low cost, low weight, mechanical strength and biodegradability. ${ }^{12,13}$ In this context, sisal fibers have been investigated as a dispersive phase in polymeric composite materials. ${ }^{14,15}$ Sisal fiber (Agave sisalana) is one of the most widely used natural fibers for the production of ropes and carpets and is very easily cultivated due to its short renewal times. Nearly 4.5 million tons of sisal fibers are produced every year throughout the world mostly in Tanzania and Brazil. ${ }^{16}$ Sisal cell fiber is composed of $78 \%$ cellulose, $8 \%$ lignin, $10 \%$ hemicelluloses, $2 \%$ waxes, and about $1 \%$ ash by weight. The fibers cell wall is a composite structure of lignocellulosic materials reinforced by helical microfibrillar bands of cellulose. ${ }^{17}$ This structure gives to sisal better performance for commercial applications when compared to other natural fibers, such as a higher elastic modulus, good thermal and acoustic insulation properties, increased impact strength and moderate tensile and flexion strengths. ${ }^{18}$

In this work, $\mathrm{TiO}_{2}$ nanoparticles were synthesized and applied on sisal fibers by dip-coating process. XRD, XPS, AFM and SEM analysis were performed to determine the effects of nanotitanium deposition on fibers surface morphology and chemical composition. The photocatalytic properties and reusability of the obtained composite were also evaluated using methylene blue dye as synthetic wastewater model.

\section{Materials and methods}

\subsection{Material}

The material used in this work was Agave sisalana fibers with count number of 20 Tex. The samples were prewashed with a solution of $1 \mathrm{~g} \mathrm{~L}^{-1}$ of non-ionic detergent at $30^{\circ} \mathrm{C}$ for 30 minutes and then rinsed with distilled water for another 5 minutes, in order to minimize contamination.

\subsection{Synthesis of $\mathrm{TiO} 2$}

A $50 \mathrm{ml}$ of $7 \% \mathrm{v} / \mathrm{v}$ water solution of Titanium tetrachloride (TiCl4) was added dropwise to $35 \mathrm{~mL}$ of pure ethanol under vigorous stirring for $30 \mathrm{~min}$ at room temperature. Ammonium hydroxide was added wisely and a precipitate was obtained. After settle the solution for twelve hours the precipitate was separated, washed with deionized water to remove the chloride ions and centrifuged. The resulting solution was dried overnight at $60{ }^{\circ} \mathrm{C}$ and finally the powder was calcinated for two hours at $600{ }^{\circ} \mathrm{C}$. 


\subsection{Nanobiocomposite preparation}

An acrylic binder $(5 \mathrm{~g})$ and $\mathrm{TiO} 2$ nanoparticles $(0.10 \mathrm{~g})$ were added in $100 \mathrm{~mL}$ of water and the solution was stirred for 60 minutes. All the materials (fiber and solution) were pressed and molded into a metal sample holder with $8 \mathrm{~cm}$ of diameter. Finally the polymerization process was performed in an oven at $150^{\circ} \mathrm{C}$ during 5 minutes.

\subsection{Photocatalytic properties of the nanobiocomposite}

Methylene blue (MB, CI 52015) was applied according to ISO 10678 standard: 2010. The Sisal/TiO2 nanobiocomposite was placed in a $1 \mathrm{ppm}$ dye solution $(50 \mathrm{~mL})$ and then irradiated in a UV light box up to 150 minutes. Dye degradation was followed in a UV-Vis spectrophotometer HITACHE model U-2000 between 380-780 $\mathrm{nm}$. The measurements were carried out for 30,60, 90, 120 and 150 minutes.

\subsection{X-ray powder diffraction}

The crystalline phases of $\mathrm{TiO} 2$ were determined by using of X-ray diffractometer Schimadzu model: XRD 6000 with $\mathrm{CuKa}$ radiation in the range $20-70^{\circ}(\lambda=0.154 \mathrm{~nm})$.

\subsection{Scanning Electronic Microscopy}

Morphological analysis of Sisal/TiO2 fibers was realized by Scanning Electronic Microscopy (Schottky FEI Quanta 400FEG / EDAX Genesis X4M). Specimens were coated with a thing gold-palladium film, to avoid electrical charge accumulation during sampling.

\subsection{Atomic Force Microscopy}

AFM experiments were performed in a tapping mode in air using a multimode SPM microscope controlled by a Nanoscope III, at room temperature. Silicon cantilevers (AppNano) with a constant force between 25 and $75 \mathrm{~N} \mathrm{~m}-1$ and a resonance frequency of $339 \mathrm{kHz}$ were used.

\subsection{X-Ray Photoelectron Spectroscopy}

XPS measurements were performed on a VG Scientific ESCALAB 200A equipment. For analysis, an achromatic Al (Ka) X-ray source operating at $15 \mathrm{kV}(300 \mathrm{~W})$ was used, and the spectrometer, calibrated with reference to $\mathrm{Ag}$ $3 \mathrm{~d} 5 / 2(368.27 \mathrm{eV})$, was operated in CAE mode with $20 \mathrm{eV}$ pass energy.

\subsection{Contact angle measurement}

The water wettability of sisal treated and untreated with nanoparticles under UV irradiation were characterized with Dataphysics equipment using OCA20 software with video system for the capturing of images in static modes.

\subsection{Washing Fastness}

The washing fastness was evaluated in accordance with stipulated in standard ISO 105 C06, method A1S, at temperature of $40^{\circ} \mathrm{C}$. 


\section{Results and discussion}

The synthesis of titanium oxide nanoparticles by sol-gel method using titanium tetrachloride and ethanol revealed to be a versatile method to easily tailor particle size and surface area varying the aging time, reaction temperature and the reagents ratio. ${ }^{19}$ After calcination the nanoparticles was grinded obtaining a white powder with a good yield of $90 \%$ with respect to $\mathrm{TiCl}_{4}$. The average crystallite size was calculated by the width of the XRD peak for anatase using the Scherrer's equation. ${ }^{20}$ An annealing temperature of $600^{\circ} \mathrm{C}$ was used to obtain an intense and sharp peak (101) indicating that the crystalline phase of anatase $\mathrm{TiO}_{2}$ was successfully formed (Figure 1). Although particle size determination by peak broadening is not a very accurate method, the results coincide well with SEM observation showing an average diameter of $32 \mathrm{~nm}$.

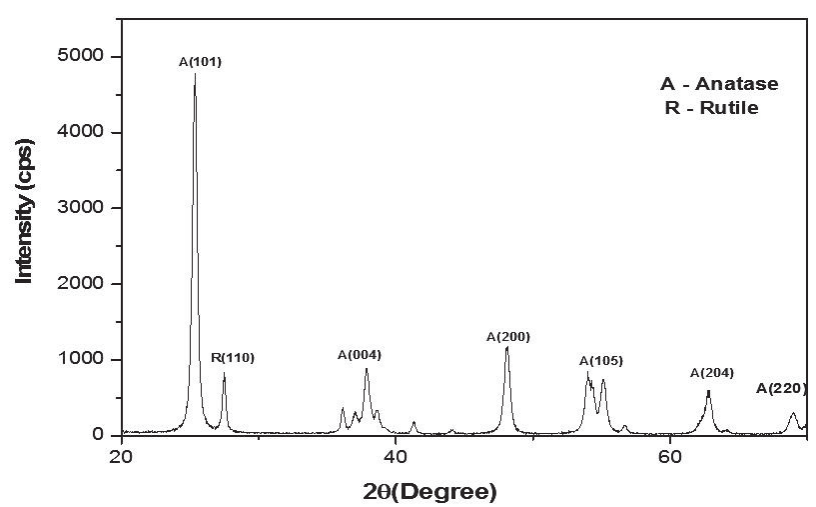

Fig. 1. X-ray difractogram of $\mathrm{TiO}_{2}$ nanoparticles.

SEM analysis was used to examine morphology and shape of nanomaterials. Figures 2 (a) and (b) show the sisal fibers $/ \mathrm{TiO}_{2}$ nanocomposite after the molding process and its microstructural analysis by SEM (10000X), respectively. It's possible to observe the formation of a continuous and uniform $\mathrm{TiO}_{2}$ coating on sisal fibers with the presence of dispersed nanoparticle agglomerates.

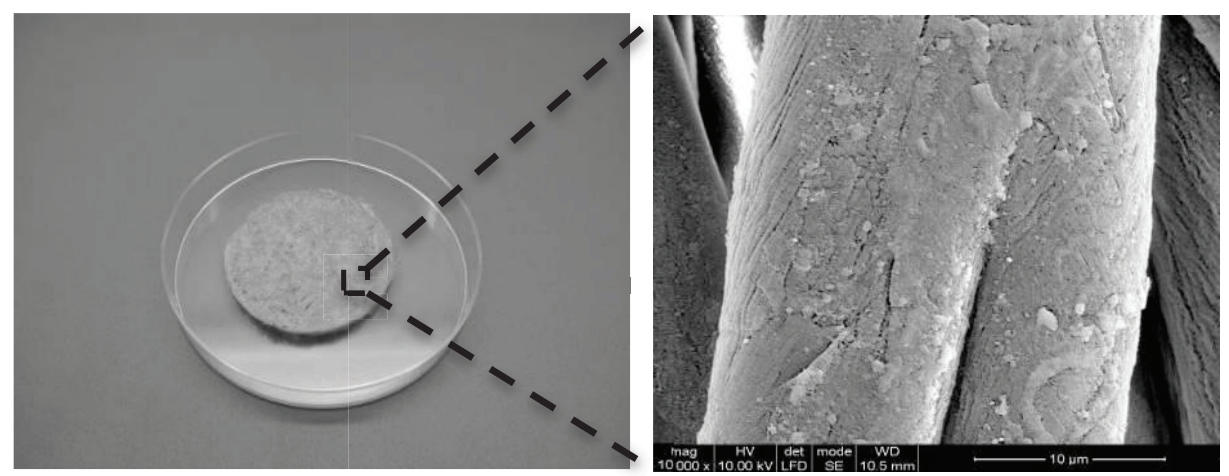

Fig. 2. (a) $\mathrm{TiO}_{2} / \mathrm{Sisal}$ molded nanocomposite and (b) SEM image of the nanocoated sisal fibers (10000 X). 
The AFM analysis of sisal before and after the $\mathrm{TiO}_{2}$ nanoparticle deposition confirms the changes in texture introduced by the addition of the single-nanoparticle top layers (Figure 3). The untreated sisal depict a ridge-andvalley morphology, while the nanocomposite show a smoother surface characterized by a highly porous and granular structure typical of cluster-assembled films, with grains diameter up to $60 \mathrm{~nm}$ that are probably aggregates of clusters partially coalesced and whose finer structure cannot be resolved by AFM. ${ }^{21}$
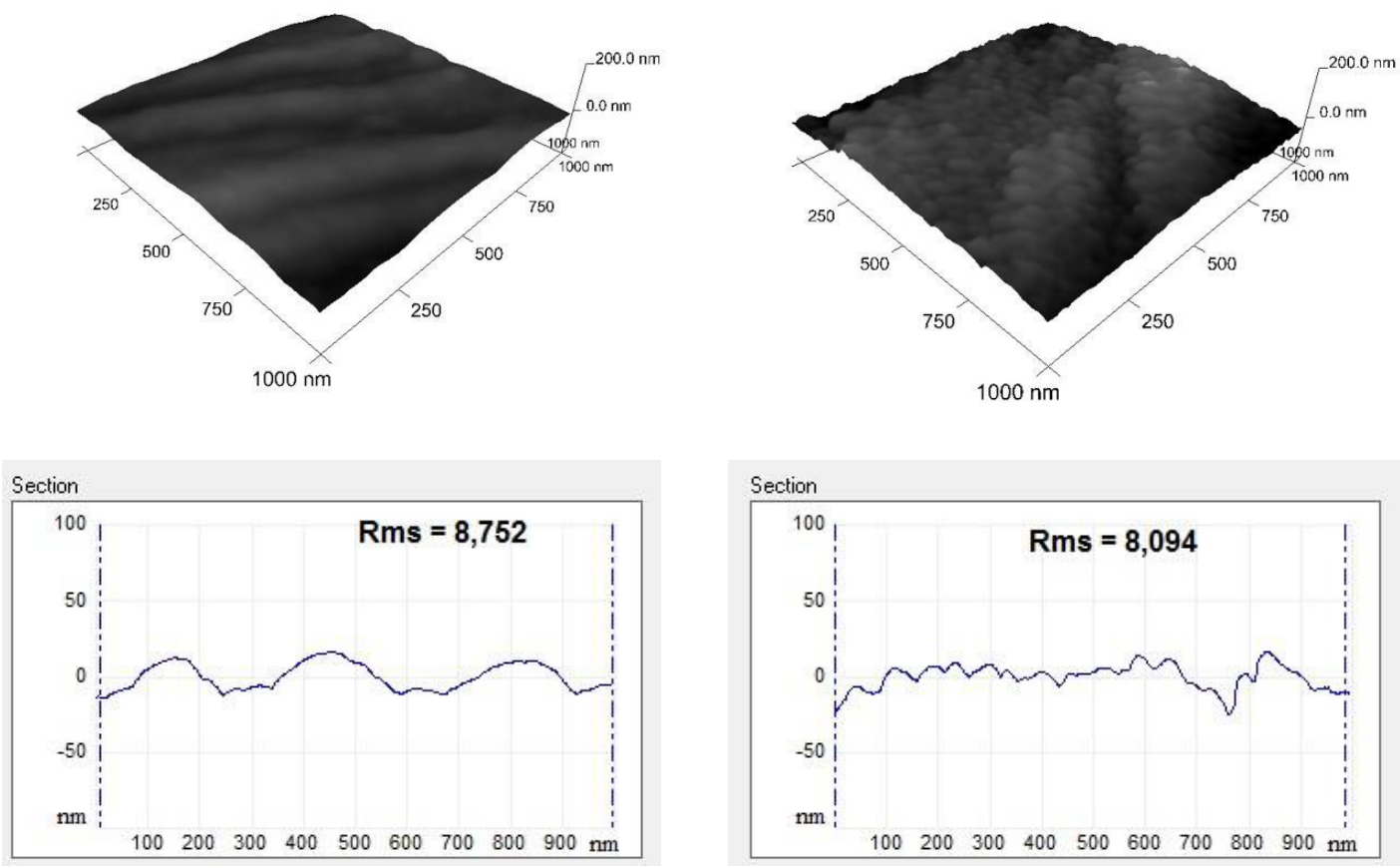

Fig. 3. AFM images, with an analysis area of $10 \times 10 \mu \mathrm{m}$, of the sisal surface before and after $\mathrm{TiO}_{2}$ nanoparticles deposition.

XPS measurements confirmed the presence of a good yield of nanocoated titanium oxide on the sisal surface (Figure 4). The absence of a chlorine peak in the XPS spectra indicates that the used high calcination temperature removed completely chlorine. The observed $\mathrm{Ti} 2 \mathrm{p}$ and $\mathrm{O} 1 \mathrm{~s}$ ratio is in accordance with the theoretical yields of titanium and oxygen of $33.33 \%$ and $66.67 \%$ respectively. ${ }^{19}$ This result, in addition to the relatively low $\mathrm{C} 1 \mathrm{~s}$ peak, confirms that the deposition of $\mathrm{TiO}_{2}$ nanoparticles was quite uniform and continuous as showed by SEM and AFM analysis. 


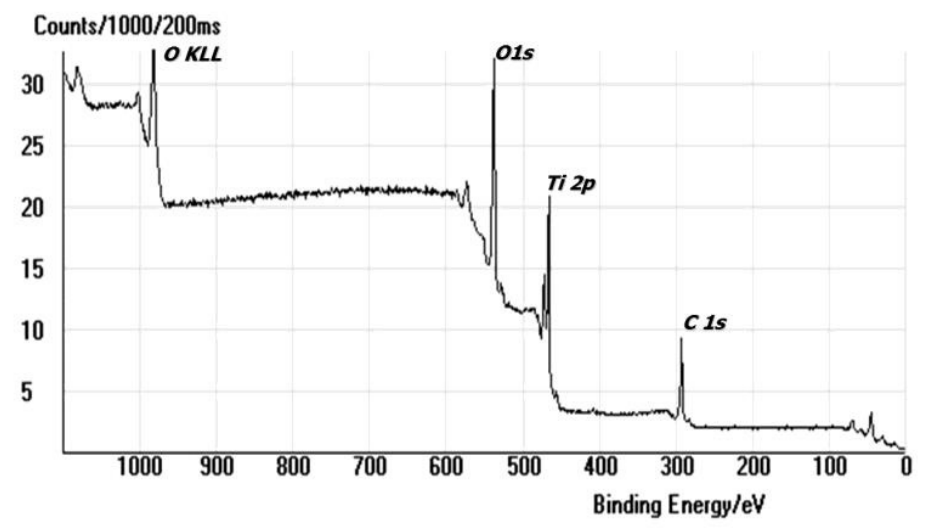

Fig. 4. XPS analysis of the $\mathrm{TiO}_{2}$ on Sisal fibers

The photocatalytic decomposition of methylene blue solution showed an excellent yield of approximately $92 \%$ after 3 hours of UV exposure (Figure 5) as previously observed. ${ }^{22,23}$ The contact angle of nanocomposite $\left(142^{\circ}\right)$ was not very different to the untreated sisal $\left(140^{\circ}\right)$ however, significant changes were observed in the water contact angle of $\mathrm{Sisal} / \mathrm{TiO}_{2}$ nanocomposite when exposed to UV irradiation. After 7 minutes of $\mathrm{UV}$ exposure the contact angle of the untreated sisal changes from $140^{\circ}$ to $111^{\circ}$ due to regular drop absorption of the sisal fibers. Differently, in the nanocoated sisal the contact angle decreases from $140^{\circ}$ to $6^{\circ}$. This behavior is well known as photo-induced hydrophilicity. ${ }^{24}$ The proposed model is based on the creation of surface oxygen vacancies at bridging sites by the action of UV irradiation, resulting in the conversion of relevant $\mathrm{Ti}^{4+}$ sites to $\mathrm{Ti}^{3+}$ sites which are favorable for dissociative water adsorption. ${ }^{25}$ However, usually this is a long process that takes several hours to achieve low contact angles. Thus, our results demonstrate an unusual fast photo-induced hydrophilicity of $\mathrm{TiO}_{2}$ nanoparticles deposited onto sisal fibers. It seems that $\mathrm{TiO}_{2}$ nanoparticles promote the formation of additional oxygen species on the sisal fiber surface enhancing its water affinity. However, other structural and chemical changes could affect water accessibility such as the creation of micro-channels, enhanced micro-roughness and reduction of glass transition temperature. The results of washing fastness after 5 cycles are quite good resulting in a methylene blue degradation yield of $70 \%$ after 3 hours of UV expsure, confirming the high level of nanoparticle fixation. Further experiment will be performed with a chemical binder in order to enhance the washing fastness and reduce the release of nanoparticles in the environment. 


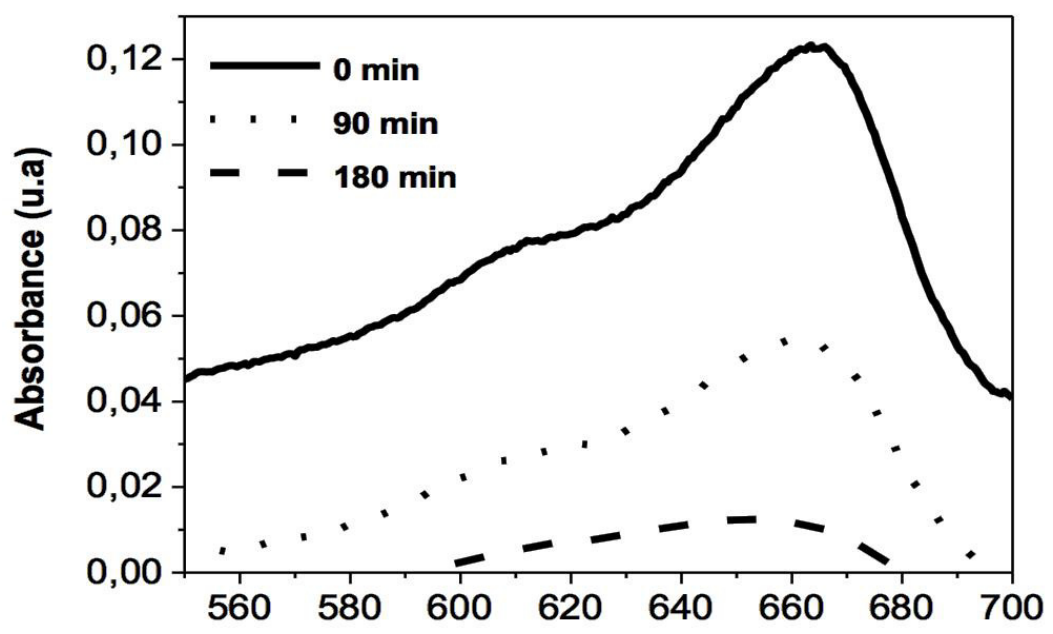

Fig. 5. UV-vis spectra of the methylene blue photodegradation at different time.

\section{Conclusions}

This work shows an efficient method to prepare $\mathrm{TiO}_{2} /$ sisal fibers nanocomposite. The results obtained by XRD, XPS, SEM and AFM analysis confirm the formation of continuous, chlorine free and uniform $\mathrm{TiO}_{2}$ nanoparticles coating on sisal fibers mostly in anatase phase with an estimated average diameter of $32 \mathrm{~nm}$. The nanocomposite display a smoother surface characterized by a highly porous and granular structure typical of cluster-assembled films, with grains diameter up to $60 \mathrm{~nm}$. The photodegradation yield of methylene blue by the UV activated nanocomposite was $92 \%$ and $70 \%$ after 5 washing cycles. The nanocomposite exhibits a remarkable fast photoinduced hydrophilicity decreasing the contact angle from $140^{\circ}$ to $6^{\circ}$ after 7 minutes of UV exposure. Thus, the development of $\mathrm{TiO}_{2}$ nanoparticles/sisal fiber nanocomposite has a remarkable potential to be applied for textile wastewater photoremediation due to its rapid kinetic, low cost, low weight, reusability, mechanical strength and biodegradability.

\section{Acknowledgment}

Andrea Zille (C2011- UMINHO-2C2T-01) acknowledges funding from Programa Compromisso para a Ciência 2008, Portugal.

\section{References}

1. $\quad$ Liuxue, Z., et al., Surface and Coatings Technology (2007) 201, 7607

2. Hua, M., et al., Journal of Hazardous Materials (2012) 211-212, 317

3. Wu, D., et al., Surface and Coatings Technology (2009) 203, 3728

4. $\quad$ El-Roz, M., et al., Catalysis Today (2013) 205, 111

5. Pasqui, D., and Barbucci, R., Journal of Photochemistry and Photobiology A: Chemistry (2014) 274, 1

6. $\quad$ Yang, J.-J., et al., Reaction Kinetics, Mechanisms and Catalysis (2013) 110 (2), 515

7. $\quad$ Pelaez, M., et al., Applied Catalysis B: Environmental (2012) 125, 331

8. $\quad$ Gupta, S. M., and Tripathi, M., Chinese Science Bulletin (2011) 56 (16), 1639

9. Han, F., et al., Applied Catalysis A: General (2009) 359 (1-2), 25 
10. Gaya, U. I., and Abdullah, A. H., Journal of Photochemistry and Photobiology C: Photochemistry Reviews (2008) 9 (1), 1

11. Faruk, O., et al., Progress in Polymer Science (2012) 37 (11), 1552

12. Carneiro, J. O., et al., Journal of Nanoscience and Nanotechnology (2011) 11 (10), 8979

13. Montazer, M., and Pakdel, E., Journal of Photochemistry and Photobiology C: Photochemistry Reviews (2011) 12 (4), 293

14. da Silva, L. J., et al., Composites Part B: Engineering (2012) 43 (8), 3436

15. Kim, J. T., and Netravali, A. N., Composites Part A: Applied Science and Manufacturing (2010) 41 (9), 1245

16. Li, Y., et al., Composites science and technology (2000) 60, 2037

17. Ramesh, M., et al., Composites Part B: Engineering (2013) 48, 1

18. Ramzy, A., et al., Composites Part B: Engineering (2014) 66, 287

19. Hayle, S. T., American Journal of Nanoscience and Nanotechnology (2014) 2 (1), 1

20. Niederberger, M., et al., Chemistry of Materials (2002) 14 (10), 4364

21. Bravo, J., et al., Langmuir (2007) 23 (13), 7293

22. Zhang, Z. B., et al., J Phys Chem B (1998) 102 (52), 10871

23. Stefanov, B. I., et al., Colloid Surface A (2011) 382 (1-3), 219

24. Wang, R., et al., Nature (1997) 388 (6641), 431

25. Zhang, L., et al., Energy \& Environmental Science (2012) 5 (6), 7491 